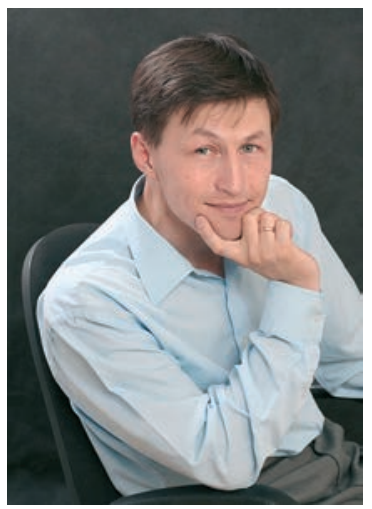

\author{
Анохов Игорь Васильевич \\ Кандидат экономических наук, доцент \\ Начальник научного управления, \\ Байкальский государственный университет, \\ 664003, Российская Федерация, г. Иркутск, ул. Ленина, 11, \\ e-mail: i.v.anokhov@yandex.ru

\section{Igor V. Anokhov} \\ $\mathrm{PhD}$ in Economics, Associate Professor \\ Head of Research Depatment, Baikal State University, \\ 11 Lenin St., 664003, Irkutsk, Russian Federation, \\ e-mail: i.v.anokhov@yandex.ru
}

\title{
ОТ СРЕДСТВ МАССОВОГО ВЕЩАНИЯ К СРЕДСТВАМ МАССОВОГО СОУЧАСТИЯ
}

Аннотация. В статье рассматриваются тенденции развития печатных средств массовой информации. В настоящее время они находятся в стадии изменения своей деятельности. Главный вызов состоит в стремительном развитии цифровых технологий, изменивших как способ донесения информации, так и само содержание изданий, а также портрет адресата печатных средств массовой информации. Печатные органы окончательно потеряли монополию на рынке информации. Более того, сегодня уже нельзя уверенно сказать, кто является автором информации: редакция газеты, комментаторы на ее сайте или случайные очевидцы какого-либо события.

В результате печатные средства массовой информации постепенно переходят от концепции одностороннего, линейного вещания к концепции «журналистики взаимодействия», в которой подготовка содержания, поиск материала и его обсуждение осуществляются внутри одного интернет-пространства. Социальные медиаресурсы по сути стирают грань между потребителями информации и ее производителями.

От того, насколько успешным будет поиск новой формы существования, зависит выживание не только отдельных изданий, но и всего социально важного сегмента рынка. Исторический обзор печатных средств массовой информации позволяет выделить определенные закономерности, которые в свою очередь дают возможность выдвигать догадки об их ближайшем будущем.

В статье предлагается применить технический подход к исследованию печатных СМИ. С этой точки зрения развитие системы средств массовой информации проходит через процесс разрешения противоречий административного, технического, физического и фринансового характера. Чаще всего такие противоречия разрешаются путем переноса всех или части функций в надсистему или в подсистему.

Ключевые слова. Медиалогия, средства массовой информации, цифровая экономика, издательство, печать, газеты. 
Информация о статье. Дата поступления 11 апреля 2017 г.; дата принятия к печати 09 октября 2017 г.; дата онлайн-размещения 30 октября 2017 г.

\title{
FROM MASS BROADCASTING TO MEDIA SHARING
}

\begin{abstract}
The article discusses trends of development of the print media. It is obvious, that currently the nature of the print media is changing. The main challenge is fast development of digital technologies, which have changed both the way of disseminating information and the contents of the print media, as well as the image of the addressee of the print media, i.e. the reader. The print media have definitely lost the monopoly on the information market. Moreover, one cannot state for sure today who is the author of a piece of information: a newspaper editor, members of the general public, leaving comments on a website, or chance witnesses to an event.

As a result, the print media are gradually shifting from the concept of one-sided linear publishing to the concept of interactive journalism, when preparing the contents, searching for material and discussing it are done within one and the same Internet environment. Social media actually blur the line between the audience and those ones who cover the news.

Surviving of some newspapers and magazines as well as the print media in general depends on whether we will succeed in finding a new form of their existence. A historical survey of the print media enables us to single out some common factors allowing to speculate about their near future.

The article proposes to apply the technical approach to the study of the print media. From this point of view, the development of the mass media system like that one of any system occurs through the resolution of administrative, technical, physical and financial contradictions. Often such contradictions are resolved by transferring all or some functions to a supersystem or to a subsystem.
\end{abstract}

Keywords. Mediology, the media, digital economy, publishing house, printing, newspapers.

Article info. Received April 11, 2017; accepted October 09, 2017; available online October 30, 2017.

В отличие от реальных фризических систем, СМИ представляют собой абстрактную или символическую систему, которая направлена на фрормирование некоторого представления о реальной системе, в меньшей или большей степени соответствующего фоктическому положению дел. Такое представление всегда неполно и отражает только некоторые аспекты реальной системы. В целом значение СМИ обусловлено «необходимостью внесения в массовое сознание, т. е. в систему сознания, функционирующего непосредственно в практике, социальных установок на основе собственных мировоззренческих парадигм, выраженных в форме их групповых идеологий» [1, с. 67].

Можно сказать, что СМИ являются для общества своеобразным зеркалом (чистым или искаженным, желаемым или отрицаемым). Общество смотрится в него и судит о самом себе через это зеркальное отражение. В результате через средства символьной системы СМИ 
происходит изменение информационно-алгоритмического состояния общества. По словам М. М. Назарова, «массовая коммуникация представляет собой институционализированное производство и массовое распространение символических материалов посредством передачи и накопления информации» [2]. Как известно, сам термин «информация» в переводе с латыни означает смену формы (или образа). Исходя из этого, продуктом символьной системы СМИ являются образы, транслируемые по разным каналам обществу и меняющие это общество.

Символьная система СМИ выполняет ряд функций. Г. Першке выделяет идеологические, культурные, социальные функции [3]. Л. Н. Федотова приписывает СМИ такие функции как информирование, воспитание, организация поведения, снятие напряжения, коммуникация [4]. И. Д. Фомичева функциями СМИ называет коммуникативную, познавательную, социально-организаторскую [5]. Е. П. Прохоров говорит, что «функции журналистики характеризуют совокупность ее обязанностей и выполняемых ею задач, способ жизнедеятельности в обществе» [6]. По мнению Н. Лумана фрункции СМИ состоят в налправлении самонаблюдения социальных систем [7].

На наш взгляд, целевой функцией СМИ является целенаправленное формирование и трансляция образов [8, с. 414]. Эти образы могут касаться разных социальных аспектов:

1. Формирования общественного мнения и идеологии;

2. Обучение население, повышение (или понижение) его уровня понимания;

3. «Тиражирование» образцов поведения.

Символьная система СМИ не самодостаточна и является частью систем более высокого иерархического уровня - надсистем (органов власти, политических партий, общественных движений и др.). В то же время она состоит из некоторого количества компонентов, которые могут быть достаточно сложны сами по себе и поэтому их можно рассматривать как систему более низкого иерархического уровня. При анализе устройства системы СМИ, мы можем переходить на все более глубокие уровни, исследуя все более дробные компоненты. Для рассматриваемой системы СМИ они будут являться подсистемами. К таким подсистемам можно отнести рецензирование, редактирование, продвижение

Автор - подготовка оригинального текста

Редактор-корректор - «вычитка» текста, проверка стилистики и др.

Главный редактор - определяет редакционную политику и содержание издания

Рецензент - оценивает и рекомендует Издатель - финансирует и публикует

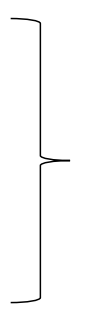

$\rightarrow$ информирование общества

(трансляция образов)

Рис. 1. Подсистемы СМИ 


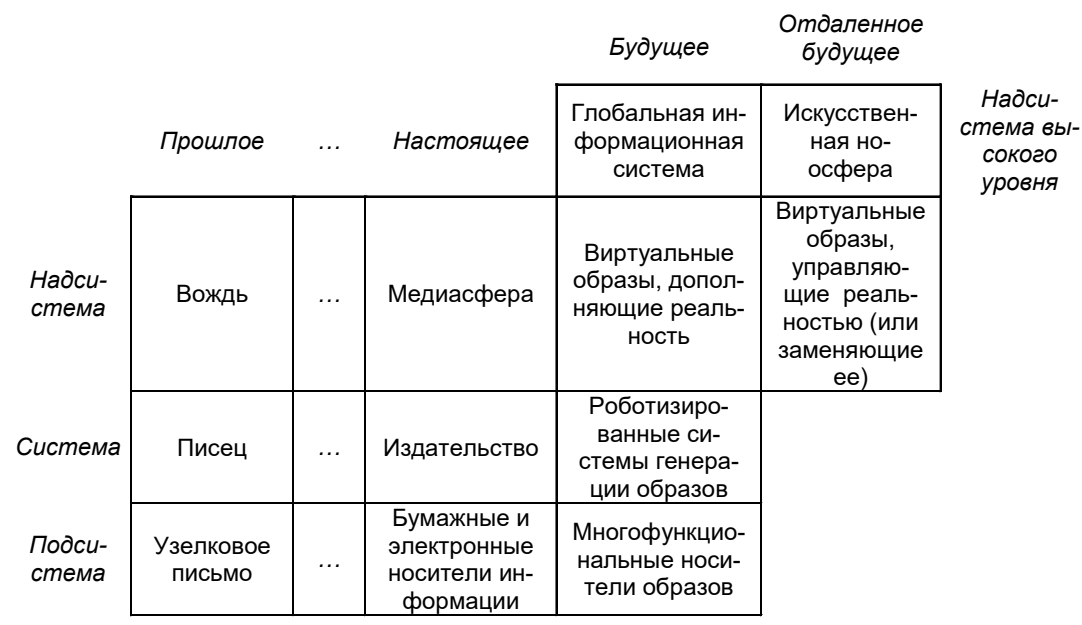

Рис. 2. Эволюция системы СМИ

органа СМИ в медиапространстве и др. Каждая из этих подсистем имеет свою узкую функцию, совокупность которых позволяет реализовать целевую функцию (рис. 1).

Символьная система СМИ может описывать реальную систему с разных позиций:

- с точки зрения ценности ее компонентов;

- С точки зрения иерархии власти;

- С точки зрения компонентов системы (без оценки ценности);

- с точки зрения аудио- и визуальных показателей (зрелищности, формы подачи и др.).

Функция информирования это обязательный атрибут любого человеческого сообщества. Соответственно система СМИ является одной из наиболее древних. Первоначально эта функция реализовывалась устно, а затем на материальном носителе - узелковое письмо, зарубки на деревянных дощечках«бирках», надписи на камне, глине, бересте, пергаменте, папирусе, на восковом слое дощечек и др.
Империи инков, например, удавалось обходится узелковой письменностью. Однако развитая система письменности позволяет несопоставимо точнее, в большем объеме и детальнее передавать информацию.

В ходе развития сама система СМИ, а также подсистемы и надсистема все более усложняются. Причем развитие системы СМИ происходит, как правило, путем переноса своих функций в надсистему или подсистему (рис. 2).

Символьную систему СМИ можно рассматривать с разных сторон. Г. Ласвелл рассматривал ее с точки зрения коммуникационного процесса: кто (коммуникатор), что говорит (сообщение), по какому каналу (средство); кому (приемник); с каким эфрфектом (эфрфект) [9].

Главным направлением развития системы СМИ является повышение идеальности - рост качества продукта и/или рост производительности при одновременном снижении затрат ресурсов.

Идеальная система СМИ это выполнение целевой функции 


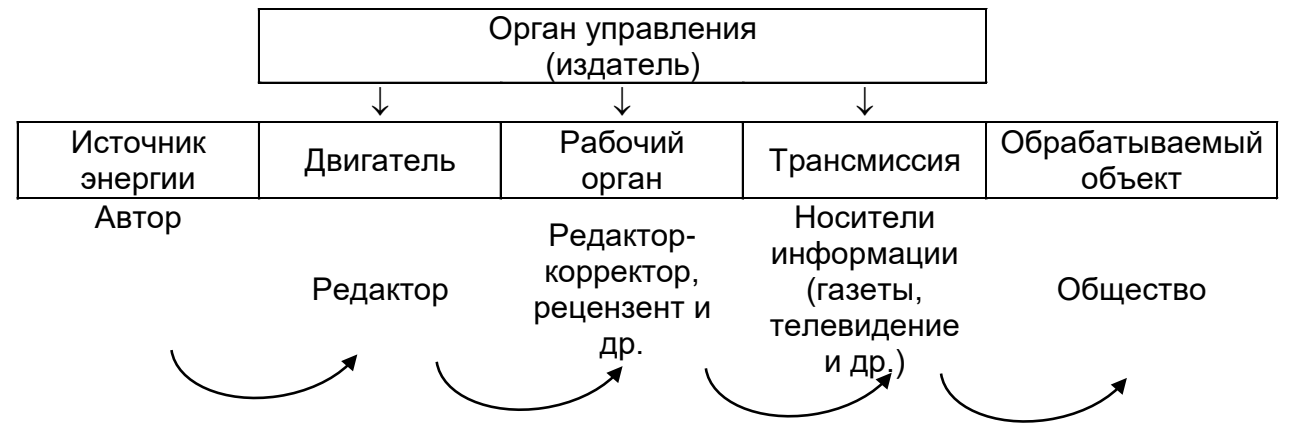

Рис. 3. Функциональная модель символьной системы СМИ

системы при отсутствии элементов системы. Другими словами, система отсутствует, a eе функция выполняется.

Для этого должен быть использован некий элемент X, который уже есть в системе (в надсистеме или подсистеме), который возьмет на себе выполнение функции. Такого рода примеры в последнее время постоянно множатся: некоторое время назад отпала необходимость печатать издания на бумаге - появились электронные сайты, в т. ч. конструкторы сайтов [10, с. 373]. Сегодня уже нет необходимости самому разрабатывать сайт: любой человек может создать собственный аналог СМИ в виде странички в Instagram, Facebook, Вконтакте и т. п. Функция выполняется, а система, которая раньше была обязательной, практически исчезла.

Рассмотрим более подробно произошедшие упрощения. Для этого выделим в символьной системе СМИ функциональные блоки, свойственные любой системе:

1. Субъект управления, запускающий процесс производства и сбыта, разрабатывающий проект для достижения цели. Применительно к системе СМИ - это издатель;
2. Источник информации - индивид, создающий информационные ресурсы. Применительно к системе СМИ - это автор;

3. Трансмиссия. Применительно к системе СМИ - это носители информации (газеты, телевидение и др.);

4. Двигатель - это субъект, определяющий в СМИ редакционную политику и содержание издания (главный редактор).

5. Рабочий орган, который осуществляет воздействие на информационные потоки в соответствии с редакционной политикой (редакторкорректор, рецензент, библиограф и др.).

Один и тот же элемент может выполнять две и более роли одновременно. И, наоборот, одна и та же роль может быть у нескольких элементов (рис. 3).

Представленная ффункциональная модель символьной системы СМИ сейчас находится под давлением цифровых технологий, как и все остальные элементы современного общества [11]. Деловые, общественные и личные массовые коммуникации все сильнее смещаются в онлайн-сфреру [12].

Существует мнение, что сегодня в России это давление еще не по- 
влекло серьезных последствий. Так, например, А. М. Даниелян считает, что «на данный момент отказ от печатной версии издания может привести к серьезным убыткам, потому что онлайн-версии изданий не стали для медиабрендов устойчивым источником дохода. За редким исключением онлайн-проекты можно рассматривать только как вспомогательный ресурс фринансирования» [13, с. 147].

Вице-президент Гильдии издателей периодической печати, член правления Всемирной ассоциации газет и медиатехнологий (WAN-IFRA) В. Гатов, полагает, что развитие коммуникационных каналов сдерживается двумя факторами:

Первый фрактор - это так называемая портативность бумажных медиа, не требующих ни электрической энергии, ни связи с какимилибо встроенными или внешними массивами данных, т. к. вся излагаемая информация уже напечатана на бумаге.

Второй фрактор: для печатных СМИ характерен не только традиционный материальный носитель и почти полностью разрушившаяся, но пока формально существующая система дистрибуции, но и отлаженный метод обработки и выдачи готовой информации через редакции [14].

Представленная на рисунке 3 функциональная модель символьной системы СМИ в современной цифровой экономике принципиальным образом изменяется под влиянием четырех ключевых технологий [15]:

1. Мобильные технологии. Мобильные устройства и беспроводные системы передачи данных дали возможность осуществлять комму- никации, выстраивать удаленную совместную работу и совершать денежные платежи вне зависимости от местонахождения.

2. Бизнес-аналитика, в основе которой лежит организация доступа пользователей к данным и анализ структурированной информации о бизнесе. Большинство из игроков этого рынка - широко известные бренды (SAS Institute, SAP, Oracle и др.). Внутренние функциональные связи автоматизируются и оцифровываются.

3. Социальные медиа. Самые удачные социальные платформы начинались с одного-единственного типа взаимодействия, который создает высокую стоимость даже при небольшом количестве контактов. К примеру, у Facebook была сначала очень узкая задача: связывать студентов Гарвардского университета с другими студентами того же университета. Потом платформу открыли для студентов вузов вообще, а затем - для всех желающих. Linkedln была поначалу профессиональной социальной сетью, а потом вышла на новые рынки подбора персонала, издательской деятельности и т. д.

4. Облачные услуги - это «предоставление повсеместного и удобного сетевого доступа к общим вычислительным ресурсам (например, к сетям, серверам, системам хранения, приложениям и сервисам), которые могут быть быстро предоставлены и освобождены с минимальными эксплуатационными затратами и при минимальном взаимодействии с провайдером услуг» [16, с. 274]. Примером в данном случае может являться компания Apple, которая с помощью App Store 
по фракту стала площадкой, которая сводит вместе разработчиков приложений и владельцев телефонов [17].

Также появились и активно развиваются такие цифровые инструменты как технологии совместной работы и технологии телеприсутствия.

Б. Меллинк использует для перечисленных выше пунктов термин Nexus of Forces, понимая под этим взаимосвязь сил: социального взаимодействия, мобильности, облачных технологий и использования больших массивов информации) [18].

В результате воздействия этих технологий функциональная модель символьной системы СМИ в современной цифровой экономике трансформируется следующим образом (рис. 4).

Как видим в ситуации с электронными социальными сетями целевую функцию взяла на себе надсистема. Идеальность системы СМИ скачкообразно выросла. Из системы исчезла трансмиссия, двигатель и рабочий орган. Их функции переместились в надсистемы. В результате традиционные печатные издания переживает серьезный кризис и теоретически могут исчезнуть из медиапространства как авторитетные СМИ.

Однако невозможно повысить идеальность всех частей сразу. Не- избежно один из элементов будет опережать остальные в развитии. В результате возникают противоречия между ним и остальными компонентами. Символьная система СМИ совершенствуется именно путем решения этих противоречий.

Рассмотрим исторический опыт развития СМИ через решение таких противоречий:

1. Необходимость передавать накопленные знания, а также развивать мореплавание, создавать карты, торговлю, вести учет товаров и т. д. блокировалась ограниченными способностями человека к запоминанию. Решением данного противоречия стало появление письменности.

2. Накопленный в средние века объем информации и необходимость его массового тиражирования ограничивались низкой скоростью работы писцов. Противоречие было устранено изобретением книгопечатанья. Результатом стал скачкообразный рост промышленности, науки, торговли и финансовых операций.

3. Рост скорости социального взаимодействия привел к резкому росту спроса на свежую, оперативную информацию, которую не могло обеспечить книгопечатание. В итоге человечество вновь совершило качественный скачок и создало газеты.

\begin{tabular}{c|c|c|}
\cline { 2 - 2 } Надсистема & \multicolumn{2}{|c|}{ Социальные сети } \\
\cline { 2 - 3 } Система & Источник энергии & $\begin{array}{c}\text { Обрабатываемый } \\
\text { объект }\end{array}$ \\
\cline { 2 - 3 } & Автор & Общество
\end{tabular}

Рис. 4. Изменившаяся функциональная модель символьной системы СМИ 
Появившийся в этот момент List of Lloyd's («Вестник страхового общества Ллойд'с) является примером «первого в мире делового СМИ, публиковавшего для своей целевой аудитории - участников этого страхового консорциума - информацию о событиях, связанных с морской торговлей, страхованием грузоперевозок и судов, мореплаванием и финансами» [19, с. 95].

Как видим, каждый новый скачок в развитии системы СМИ был основан на разрешении какого-либо противоречия.

В данный момент таким отстающим компонентом системы СМИ (в сегменте социальных медиа) является автор - в условиях отсутствия редакции печатного СМИ среднее качество публикаций упало до минимума. Дешевизна контента и его доступность оборачиваются девальвацией информации, вызванной ее переизбытком. Несколько выправляет ситуацию система рейтингов, позволяющая выделить наиболее интересных и продуктивных авторов, которые по количеству подписчиков иногда обходят крупные органы печати.

Исходя из этого, следующий скачок в идеальности символьной системы СМИ будет заключаться в преодолении противоречий между недостаточным уровнем профессионализма авторов и резко повысившимися возможностями надсистемы.

Для этого необходимо решить ряд противоречий:

1. Административное противоречие. Автор иерархически никому не подчиняется. Законодательство дает ему очень широкие возможности воздействия на общество. При этом создаваемые автором образы могут нести скрытый разрушительный потенциал. Однако поставить административный постоянный надзор над сотнями тысяч авторов проблематично, несмотря на цифровые технологии, т. к. здесь требуется семантический контроль.

2. Техническое противоречие улучшение какого-либо свойства системы ухудшает другое свойство. В данном случае противоречие выглядит следующим образом: чтобы быть востребованным у общества самодеятельный автор должен создавать плотный поток образов и публикаций, однако, чтобы сохранить популярность требуется высокое качество образов, что автоматически уменьшает публикационную активность.

3. Физическое противоречие. К одному и тому же свойству системы предъявляются взаимоисключающие требования, обусловленные законами природы. Автор не способен фризически одновременно и в одиночку заниматься творчеством, критически оценивать его, продвигать в медиассрере, осуществлять «вычитку», окупать затраты, контактировать с подписчиками и др.

4. Финансовое противоречие. Посвящая значительную часть своего времени публикационной деятельности (большей частью неоплачиваемой) автор нуждается в финансовой поддержке. При этом «только 5\% интернет-пользователей согласны платить за чтение новостей в Интернете» [20, с. 45]. По этой причине печатные издания основную часть своих доходов в сети получают с помощью рекламы, но этот источник не всегда доступен независимому автору. 
В связи с вышеизложенным возникает вопрос: способна ли современная теория журналистики дать соответствующий жизни рецепт разрешения данных противоречий? На наш взгляд, с изменением объекта исследования (т. е. общества) должен качественно измениться и субъект исследования (т. е. журналистика). Скачкообразное изменение качества массовых коммуникаций делают необходимым «синтез теории СМИ и теории журналистики, возвышающий над собой теорию управления массмедиа» [1, с. 283284]. Модификация совокупности технологических средств и приемов, служащих для массовых коммуникаций сегодня модифицирует журналистский контент [21, с. 267]. Результатом такого синтеза должна быть новая наука - медиалогия [22, c. 10].

Используя инструментарий журналистики и теории массовых коммуникаций, медиалогия должна разрешить указанное выше противоречие между автором и обществом. Возможно в рамках этой новой науки будет найден рецепт устранения противоречия через ликвидацию роли профессионального, узкоспециализированного автора-журналиста. В итоге общество само станет автором информации и его потребителем. Сегодня общество в целом готово не только потреблять, но и поставлять информацию: читатель стал журналистом, потребитель информации - eе производителем. Появился новый тип журналистики — гражданская, публичная журналистика, в которой любой очевидец значимого события имеет возможность выступить в роли профессионального репортера, а читатель - в роли ретранслятора (распространителя) сведений. Интернет из пространства, где получают информацию, трансформировался в среду, где ее создают и распространяют.

Признаком такого перехода является рост цитирования интернет-блогов в традиционных СМИ. В результате сегодня появился термин «журналистика соучастия», в которой создание контента, «сбор информации, обсуждение редакционных вопросов, написание текстов» [23, с. 53] осуществляется вместе с непрофрессиональными журналистами. Возможность для читателей комментировать статью, голосовать, размещать собственный материал сегодня стала практически реализуемой. Традиционная газета из авторитета, изрекающего истину, превращается в место беседы гражданских журналистов, которые предоставляют свои собственные материалы и приходят сюда делиться новостями с другими людьми.

Медиалогия должна разработать для гражданских журналистов систему избирательных стимулов (положительных или отрицательных), применяемых в зависимости от их вклада в общественное или клубное благо. Целью системы стимулов является изменение матрицы выигрышей таким образом, чтобы стратегия сотрудничества и соучастия была выгоднее, чем оппортунистическая.

Рассмотрим данный подход на примере печатных научных журналов, целевой аудиторией которого является достаточно узкий круг ученых из какого-либо раздела науки, например, математики.

В настоящее время ученые публикуют в такого рода журналах свои 
научные статьи бесплатно или даже доплачивая за это. Очевидно, что стимулом к вложению интеллектуальных сил является не материальная выгода, а социальный капитал и репутация. При этом в рецензируемых журналах каждая статья проходит фильтрацию в виде «слепого» рецензирования от другого авторитетного в данной сфрере ученого, который в свою очередь также принуждается к написанию статей и, следовательно, через некоторое время сам становится автором. В результате этого одни и те же люди чередуют роли авторов и рецензентов.

Таким образом в данной сфере возникают такие явления как взаимозависимость и репутация. Возникает малая группа (в терминах институциональной экономики), члены которой связаны множеством видов отношений и озабочены желанием повысить или сохранить свою репутацию. В свою очередь они могут осуществить это, оказывая взаимные услуги (рецензируя чужие статьи и публикуя свои, принимая участие в конференциях и др.). Признание других ученых становится основой для самооценки и самоуважения.

Другими словами, возникает своего рода клуб, члены которого оказывают друг другу разного рода услуги. Смыслом этого клуба является создание клубного блага в виде взаимной поддержки репутации, продвижения членов клуба в общественных структурах, в научно-образовательных организациях и т. п. Облегчает этот путь высокая однородность группы, складывающейся вокруг того или иного источника информации.
Следствием этого является падение взаимных требований, снижение качества публикаций при одновременном их шифровании с помощью наукообразной терминологии, недоступной для понимания обществом. В результате клуб меняет матрицу выигрышей в свою пользу за счет общества. Другими словами, такой клуб ухудшает жизнеспособность общества и паразитирует на нем.

Ликвидировать этот паразитизм должна медиалогия, которая «имеет своей задачей обеспечение здорового образа жизни человечества в системе глобальных социальных коммуникаций» [21, с. 284]. C этой целью медиалогия должна выполнять общественно-полезные функции:

1. Выявлять общественные потребности и проблемы;

2. Формулировать цели общества в отношении выявленных потребностей и проблем;

3. Принимать на себя весь спектр обратных связей;

4. Способствовать формированию в обществе устремлённости в будущее и эффрективности личностной познавательно-творческой культуры;

5. Способствовать формированию в обществе диалектической культуры познания и творчества.

Благодаря реализации этих функций медиалогии, медиапространство должно стать «соединительной и нервной тканью» общества. Для этого необходимо, чтобы медиологи разработали инструментарий, дающий возможность гражданским журналистам:

- уделять значительное время журналистике, но при этом не зависеть от редакции; 
- получать материальную поддержку, но при этом создавать материалы бесплатно;

- повышать свой профессиональный уровень, но при этом не становиться профессиональным журналистом.

Для достижения этого необходимо, чтобы в обществе существовала:

1) потребность получать такого рода некорпоративную информацию;

2) система общедоступных сведения для освоения журналистских знаний;

3) возможность накопления и передачи навыков в обществе.

Представляется, что развитие медиалогии и символьной системы СМИ будет происходить через переход в подсистему. Автор в этом случае должен перейти от монофункции - производство образов - к бифункциям - производство образов и их редактирование («вычитка» текста, проверка стилистики и др.), а затем к полифункциям - производство образов, их редактирование, рецензирование, фринансирование, продвижение и др.

Другими словами, Автор должен стать гибкой и динамичной системой, что обеспечивается множеством подсистем и новыми способами связей с обществом и надсистемой. В этой связи на медиалогию возлагается задача разработки нового способа передачи образов от Автора к обществу.

Основные современные способы связи в СМИ (устная речь, печатный текст, видеоряд) крайне неэффективны по нескольким причинам:

1. Они маломощны в смысле объема передаваемой информации в единицу времени. Попытки макси- мально их использовать приводят к информационной перегрузке;

2. Они приводят к искажению при передаче информации между лицами, даже находящимися в одном смысловом поле. Получатель информации должен дешифровать информацию от другого лица и перевести в свою систему кодировки образно-логического мышления. Разное понимание терминов, отличие в доминирующем канале связи конкретного человека (аудиальный, визуальный, кинестетический), эмоциональный фон и другие факторы ведут к неудовлетворительному состоянию общественных коммуникаций;

3. Они дают широкие возможности для фильтрации и манипулирования как со стороны отправителя, так и со стороны получателя. «Кинесические, проксемические, интонационные, вегетативные речения как проявление внутреннего психологического состояния коммуниканта манифестируют процесс изменения психических состояний человека, его отношения к партнеру в ситуации общения» [24, с. 80], но они же в первую очередь и вводят в заблуждение.

Назрела потребность в новых способах трансляции образов с помощью современных цифровых технологий. Такие новые способы передачи информации как блоги, вебсайты, СМС, электронная почта, видеоконференции и др. значительно обогатили технологию трансляции образов и привели к сплошной коммуникации всех со всеми. Но сегодня этого недостаточно: от системы СМИ требуется новый канал трансляции образов с принципиально новыми свойствами, не требующий редактирования, «вычитки», рецен- 
зирования, сохраняющий первоначальные образы без искажений.

Медиалогия в плане поиска нового способа трансляции образов должна соединить два полюса, на одном из которых находится живопись и музыка, а на другом сухие логические массивы информации, например, в виде статистических баз данных. Преимущество живописи и музыки состоит в сохранении неискаженных образов, но это же оборачивается недостатком в виде малой практической полезности. Логические массивы информации ценны своей практичностью, но часто являются «вещью в себе» и слабо отражают включенность в универсальность Мироздания.
По какому пути может пойти медиалогия в этом вопросе сегодня трудно сказать. В рамках концепции трансгуманизма рассматривается возможность дополнить биологическую природу человека техническими средствами, которые в перспективе могут позволить передавать образы от индивида к индивиду напрямую через встроенные в тело технические передатчики. Сторонники концепции, согласно которой человек еще не полностью проявил свои внутренние способности, предполагают возможность не технической, а телепатической передачи образов. Возможно существуют и другие пути, которые будут обнаружены медиалогией.

\section{СПИСОК ИСПОЛЬЗОВАННОЙ ЛИТЕРАТУРЫ}

1. Науменко Т. В. Массовая коммуникация: теоретико-методологический анализ / Т. В. Науменко. - М. : Перспектива, 2003. - 254 с.

2. Назаров М. М. Массовая коммуникация и общество: введение в теорию исследований / М. М. Назаров. - М. : Аванта-плюс, 2004. - 428 с.

3. Першке Г. Журналистика как отрасль духовного производства / Г. Першке // Основные понятия теории журналистики. - М., 1993.

4. Федотова Л. Н. Общественное мнение и журналистика / Л. Н. Федотова. - М. : Изд-во Моск. ун-та, 2011. - 376 с. $335 \mathrm{c}$.

5. Фомичева И. Д. Социология СМИ / И. Д. Фомичева. - М. : Аспект Пресс, 2007. -

6. Прохоров Е. П. Введение в теорию журналистики / Е. П. Прохоров. - М. : РИПхолдинг, 2000. - 208 с.

7. Луман Н. Реальность массмедиа / Н. Луман ; пер с нем. А. Ю. Антоновского. М. : Праксис, 2005. - 256 с.

8. Гидденс Э. Социология / Э. Гидденс. - М. : УРСС, 1999. - 704 с.

9. Lasswell H. D. The structure and function of communication in society / H. D. Lasswell // The Communication of Ideas / ed. L. Bryson. — New York, 1948. — P. 215-228.

10. Артемчук Н. Д. Обзор облачных CMS для создания сайтов / Н. Д. Артемчук // Интернет-маркетинг. - 2014. — № 6. - С. 372-376.

11. Sondergaard P. Many CIOs Are Unprepared for the Next Era in Enterprise iT [Electronic resource] / P. Sondergaard. - Access mode: http://www.forbes.com/sites/ gartnergroup/2014/02/11/many-cios-are-unprepared-for-the-next-era-in-enterprise-it/.

12. Krigsman M. Research: $\mathrm{ClOs}$ and the «Digitalization» of Business [Electronic resource] / M. Krigsman. - Access mode: http://www.zdnet.com/research-cios-and-thedigitalization-of-business-7000025454/.

13. Даниелян А. М. Диверсификация каналов коммуникации как способ сохранения аудитории печатных СМИ / А. М. Даниелян // Реклама. Теория и практика. - 2015. № 3. - С. 146-159. 
14. Гатов В. Умерла ли бумажная пресса? [Электронный ресурс] / В. Гатов. — Режим доступа: http://lenta.ru/conf/gatov.

15. The new digital economy: How it will Transform Business [Electronic resource]. Access mode: http://www.pwc.com/gx/en/technology/publications/assets/the-new-digitaleconomy.pdf.

16. Мосендз Т. А. Вычислить облако: сущность и ключевые аспекты применения облачных технологий / Т. А. Мосендз. // Менеджмент сегодня. — 2012. — № 5. — С. $274-$ 285.

17. Mell P. The NIST Definition of Cloud Computing [Electronic resource] / P. Mell, T. Grance. - Access mode: http://csrc.nist.gov/publications/nistpubs/800-145/SP800145.pdf.

18. Mellink B. The Nexus of Forces: Gartner Point of View [Electronic resource] /

B. Mellink. - Access mode: http://www.bsb.com/2013-bsb-convention-presentations.

19. Бровко С. Л. Инновационные коммуникации в инновационном социуме / С. Л. Бровко // Менеджмент инноваций. - 2013. - № 2. - С. 94-104.

20. Климина И. А. Пресса в цифровую эпоху: трансформация печатных СМИ / И. А. Климина // Интернет-маркетинг. - 2011. — № 1. - С. 44-51.

21. Суходолов А. П. Медиалогия - наука будущего / А. П. Суходолов, М. П. Рачков // Вопросы теории и практики журналистики. - 2017. - Т. 6, № 3. - С. 267-286. DOI: 10.17150/2308-6203.2017.6(3).267-286.

22. Суходолов А. П. К созданию теории средств массовой информации: постановка задачи / А. П. Суходолов, М. П. Рачков // Вопросы теории и практики журналистики. 2016. — T. 5, № 1. - C. 6-13. — DOI: 10.17150/2308-6203.2016.5(1).6-13.

23. Свищёва М. Н. Технологии адаптации традиционных СМИ к росту влияния социальных медиа в России / М. Н. Свищёва // Интернет-маркетинг. - 2014. - № 1. C. $50-61$.

24. Музычук Т. Л. Эмоциональное состояние персонажа как объект лингвистического наблюдения / Т. Л. Музычук // Вестник Московского университета. - Серия 9: Филология. - 2011. — № 1. - С. 75-88.

\section{REFERENCES}

1. Naumenko T. V. Massovaya kommunikatsiya: teoretiko-metodologicheskii analiz [Mass Communication: The Theoretical-Methodological Analysis]. Moscow, Perspektiva Publ., 2003. $254 \mathrm{p}$.

2. Nazarov M. M. Massovaya kommunikatsiya i obshchestvo: vvedenie v teoriyu issledovanii [Mass Communication and Society: Introduction to the Theory of Research]. Moscow, Avanta-plyus Publ., 2004. 428 p.

3. Pershke G. Journalism as a Branch of Spiritual Production. Osnovnye ponyatiya teorii zhurnalistiki [Basic Concepts of the Theory of Journalism]. Moscow, 1993. (In Russian).

4. Fedotova L. N. Obshchestvennoe mnenie i zhurnalistika [Public Opinion and Journalism]. Moscow, Lomonosov Moscow State University Publ., 2011. 376 p.

5. Fomicheva I. D. Sotsiologiya SMI [Sociology of the Media]. Moscow, Aspekt Press Publ., 2007. 335 p.

6. Prokhorov E. P. Vvedenie $v$ teoriyu zhurnalistiki [Introduction to the Theory of Journalism]. Moscow, RIP-kholding Publ., 2000. 208 p.

7. Luhmann N. Die Realitat der Massenmedien fur Sozialwissenschaften. Wiesbaden, Fachverlage Gmbh, 2004. (Russian ed.: Luman N. Real'nost' massmedia. Moscow, Praksis Publ., 2005. 256 p.).

8. Giddens A. Sociology. $2^{\text {th }}$ ed. Cambridge, Polity Press, 1989. 815 p. (Russian ed.: Giddens E. Sotsiologiya. Moscow, URSS Publ., 1999. 704 p.).

9. Lasswell H. D. The structure and function of communication in society. In Bryson L. (ed.) The Communication of Ideas. New York, 1948. P. 215-228.

10. Artemchuk N. D. A Survey of Cloud CMS for Creating Websites. Internet-marketing = Internet Marketing, 2014, no. 6, pp. 372-376. (In Russian). 
11. Sondergaard P. Many CIOs Are Unprepared for the Next Era in Enterprise iT. Available at: http://www.forbes.com/sites/gartnergroup/2014/02/11/many-cios-are-unprepared-forthe-next-era-in-enterprise-it/.

12. Krigsman M. Research: ClOs and the «Digitalization» of Business. Available at: http:// www.zdnet.com/research-cios-and-the-digitalization-of-business-7000025454/.

13. Danielyan A. M. Diversification of Communication Channels as a Way of Keeping the Audience of the Print Media. Reklama. Teoriya i praktika = Advertising. Theory and Practice, 2015, no. 3, pp. 146-159. (In Russian).

14. Gatov V. Have the Print Media Died? Available at: http://lenta.ru/conf/gatov.

15. The new digital economy: How it will Transform Business. Available at: http://www. pwc.com/gx/en/technology/publications/assets/the-new-digital-economy.pdf.

16. Mosendz T. A. Cloud Computing: the Essence and Key Aspects of the Application of Cloud Technologies. Menedzhment segodnya = Today's Management, 2012, no. 5, pp. 274285. (In Russian).

17. Mell P., Grance T. The NIST Definition of Cloud Computing. Available at: http://csrc. nist.gov/publications/nistpubs/800-145/SP800-145.pdf.

18. Mellink B. The Nexus of Forces: Gartner Point of View. Available at: http://www.bsb. com/2013-bsb-convention-presentations.

19. Brovko S. L. Innovative Communication in Innovative Society. Menedzhment innovatsii = Innovation Management, 2013, no. 2, pp. 94-104. (In Russian).

20. Klimina I. A. The Print Media in the Digital Era: Transformation of the Print Media. Internet-marketing, 2011, no. 1, no. 44-51. (In Russian).

21. Sukhodolov A. P., Rachkov M. P. Mediology as a Science of the Future. Voprosy teorii i praktiki zhurnalistiki $=$ Theoretical and Practical Issues of Journalism, 2017, vol. 6, no. 3, pp. 267-286. DOI: 10.17150/2308-6203.2017.6(3).267-286. (In Russian).

22. Sukhodolov A. P., Rachkov M. P. To Create a Theory of the Media: Statement of the Problem. Voprosy teorii i praktiki zhurnalistiki $=$ Theoretical and Practical Issues of Journalism, 2016, vol., 5, no. 1, pp. 6-13. DOI: 10.17150/2308-6203.2016.5(1).6-13. (In Russian).

23. Svishcheva M. N. Technologies of Adapting the Traditional Media to the Growing Influence of Social Media. Internet-marketing, 2014, no. 1, pp. 50-61. (In Russian).

24. Muzychuk T. L. A Character's Emotional State as an Object of Linguistic Observation. Vestnik Moskovskogo universiteta. Seriya 9. Filologiya = Moscow State University Bulletin. Series 9. Philology, 2011, no. 1, p. 75-88. (In Russian).

\section{ДЛЯ ЦИТИРОВАНИЯ}

Анохов И. В. От средств массового вещания к средствам массового соучастия / И. В. Анохов // Вопросы теории и практики журналистики. - 2017. - Т. 6, № 4. - С. 482495. DOI: 10.17150/2308-6203.2017.6(4).482-495.

\section{FOR CITATION}

Anokhov I. V. From Mass Broadcasting to Media Sharing. Voprosy teorii i praktiki zhurnalistiki $=$ Theoretical and Practical Issues of Journalism, 2017, vol. 6, no. 4, pp. 482-495. DOI: 10.17150/2308-6203.2017.6(4).482-495. (In Russian). 